\title{
В.М. Гилев
}

Российский государственный профессионально-педагогический университет, Екатеринбург, Россия

\section{ВИРТУАЛЬНЫЕ МАШИНЫ: АНАЛИЗ ДИДАКТИЧЕСКИХ ПРИНЦИПОВ}

Рассмотрены общепризнанные дидактические принципы, рассмотрены идея о применении виртуальных машин в образовательном процессе, а также дидактические принципы, положенные в основу использования виртуальных машин.

Статья посвящена одному из важных направлений применению дидактических принципов в виртуальных машинах. Была сделана попытка обосновать применение дидактических принципов к работе виртуальных машин, имеющих непосредственное использование в информационных процессах. В этом состоит смелая идея поставить дидактические принципы на службу одному из важнейших программных решений на сегодняшний день - виртуальным машинам.

Дальнейшее развитие и внедрение настоятельно требуют поиска новых подходов и пересмотра устоявшихся в дидактике принципов обучения.

В современных условиях образовательный процесс требует постоянного совершенствования. Образовательная деятельность в настоящий момент тесно связана с процессом информатизации, а в силу быстрого темпа развития информационных технологий их применение в образовательном процессе не всегда возможно своевременно осуществить. В связи с этим возникает потребность в использовании программных средств, призванных помочь организации учебного процесса. Этим и другим вопросам посвящена данная статья.

Ключевые слова: принцип обучения, информационные технологии, дидактический принцип, виртуальная машина, профессиональная мобильность, информатизащия.

\section{V.M. Gilev}

Russian State Vocational Pedagogical University, Yekaterinburg, Russia

\section{VIRTUAL MACHINES: ANALYSIS OF DIDACTIC PRINCIPLES}

This article describes the generally recognized didactic principles, the idea of the use of virtual machines in the educational process is considered, as well as didactic principles underlying the use of virtual machines.

The article is devoted to one of the important areas of application of didactic principles in the VMs. An attempt was made to justify the use of didactic principles to the virtual machines that have direct application in information processes. This is a bold idea - didactic principles put at the service of one of the major policy decisions today - virtual machines.

Further development and implementation requires new approaches and review of the traditional didactic principles.

In modern conditions the educational process requires continuous improvement. Educational activities are currently closely associated with the process of informatization, but due to the rapid pace of development of information technologies, their implementation in the educational process is not always possible in a fast-and-ready way. In this regard, there is a need to use software tools designed to help the organization of educational process. This and other related issues are raised in the article.

Keywords: principle of learning, information technology, didactic principles, virtual machine, professional mobility, informatization. 
Педагогические принципы служат теоретической основой практической деятельности, следование которым помогает наилучшим образом достигать поставленных целей. На сегодняшний день формулирование педагогических принципов - это результат исследования всего исторического опыта образовательной деятельности. Принцип обучения является руководящей идеей современного уровня образования и направлен на подготовку специалиста, отвечающего требованиям сегодняшнего дня.

Развитие и внедрение в образовательный процесс информатики и новых средств обучения настоятельно требуют поиска новых подходов и пересмотра устоявшихся в дидактике принципов обучения.

Обращаясь к советской педагогике (Е.А. Голант, М.А, Данилов, И.Я. Лернер, П.И. Подласый, Ю.К. Бабанский и др.), отметим, что «принципы обучения исторически конкретны и отражают насущные общественные потребности. Под влиянием социального прогресса и научных достижений, по мере выявления новых закономерностей обучения, накопления опыта работы учителей они видоизменяются, совершенствуются» [2, с. 444].

«Принципы педагогического процесса отражают основные требования к организации педагогической деятельности, указывают ее направление, а в конечном итоге помогают творчески подойти к построению педагогического процесса» [3, с. 174].

«В основе принципов обучения лежат уже познанные законы и закономерности. Многие педагогическое законы и закономерности настолько многогранны, что из них выводится не один, а несколько принципов. На разработку принципов влияют не только педагогические, но и социальные, философские, логические, психологические и иные закономерности. Они обуславливаются также целями образования и воспитания, условиями среды, уровнем развития науки, характером освоенных обществом средств и способов обучения и, конечно, самой практикой, опытом обучения» [4, с. 195].

Принципы обучения выступают в органическом единстве, образуя некоторую концепцию дидактического процесса, которую можно представить, как систему, компонентами которой они являются [2].

Анализ исследователей нового времени позволяет выделить в качестве основополагающих, общепризнанных следующие принципы [2]:
1) научности,
2) сознательности и активности,
3) наглядности,
4) систематичности и последовательности,
5) прочности,
6) доступности,
7) связи теории с практикой. 
Наряду с общепризнанными дидактическими принципами следует указать такие, как комплексность, интегративаность, алгоритмизация.

Главными характеристиками выпускника любого образовательного учреждения являются его компетентность и профессиональная мобильность.

Под компетентностью понимается интегративное качество личности, сформированное на основе совокупности предметных знаний, умений, опыта, отраженных в теоретико-прикладной подготовленности к их реализации в деятельности на уровне функциональной грамотности (Э.Ф. Зеер, А.В. Хуторской).

Под профессиональной мобильностью понимается интегративное качество личности, объединяющее в себе: сформированную внутреннюю потребность в переменах, способности, личностные качества, а также знания, определяющие готовность и решительность в определении базовых вопросов жизни и своей профессиональной сферы деятельности (М.И. Дьяченко, Е.А. Климов, Д.В. Чернилевскй, Л.А. Кандыбович, А.К. Маркова, Э.Ф. Зеер и др.) [5].

Современное материальное производство и другие сферы человеческой деятельности все больше нуждаются в информационном обслуживании, переработке огромного количества информации. Развитие компьютерной техники является необходимой составляющей процесса информатизации общества, в которой компьютер является универсальным техническим средством обработки информации любой сложности, который усиливает интеллектуальные возможности человека и общества [6].

В настоящее время образовательный процесс требует постоянного совершенствования. Образовательная деятельность в настоящий момент тесно связана с процессом информатизации, а в силу быстрого темпа развития информационных технологий их применение в образовательном процессе не всегда возможно своевременно осуществить. В связи с этим возникает потребность в использовании программных средств, призванных помочь организации учебного процесса.

Процесс интеграции новых информационных технологий в образовательный процесс достигается с помощью внедрения специальных программных средств. Для этого служат, в частности, виртуальные машины.

Использование виртуальных машин позволяет существенно расширить спектр учебных задач и улучшить качество подготовки выпускников, в частности, специалистов в области информационных технологий.

Виртуальная машина представляет собой набор программных средств, имитирующих работу реального компьютера. По сути, работа с виртуальной машиной ничем не отличается от работы с реальной, и в связи с этим создается полная иллюзия работы с реальным компьютером [6].

Виртуальная машина имеет свой BIOS, оперативную память, жесткий диск (выделенные из реального компьютера) и способна эмулировать периферийные устройства [8, с. 49]. 
Виртуальные машины позволяют запускать одновременно на одном реальном компьютере несколько различных операционных систем или конфликтующих друг с другом приложений.

Говоря о виртуальных машинах, следует разобраться, что представляет собой понятие виртуализация. Виртуализация представляет собой возможность запуска на физическом компьютере несколько изолированных друг от друга виртуальных машин, каждая из которых представляет собой полноценный компьютер, работающий на отдельном физическом компьютере.

Взаимодействие виртуальных машин с реальным аппаратным обеспечением компьютера осуществляется через монитор виртуальных машин или гипервизор, через который происходит связь виртуальных машин с реальным компьютером. Гипервизор может работать как в операционной системе реального компьютера, так и без нее, т.е. гипервизор устанавливается поверх аппаратного обеспечения реального компьютера [9].

Операционную систему физического компьютера относительно операционной системы виртуальной машины принято называть основной или «хостовой» операционной системой, а систему, установленную на виртуальную машину, принято называть гостевой операционной системой [10].

Применение виртуальных машин, а также анализ дидактических принципов позволяют обозначить принципы использования виртуальных машин в образовательном процессе.

- принцип научности - использование виртуальных машин требует развития у обучаемых компетенций научного поиска, связанного с рациональным использованием аппаратных ресурсов компьютера. Также использование виртуальных машин направлено на поиск решений, связанных с практико-ориентированными классами задач;

- принцип алгоритмизации предполагает, что учебный процесс, как и решение любой задачи, представляет собой четко структурированный набор действий, для достижения результата - целей обучения. В решении типовой задачи, преподаватель руководствуется порядком действий, т.е. алгоритма следования шагов для получения результата. Любое обучение также следует рассматривать как совокупность действий: как; в какой последовательности, с помощью каких средств, методов достигаются цели обучения;

- принцип доступности - использование виртуальных машин дает возможность использования в учебном процессе любых программ, поскольку в виртуальной машине можно использовать различные операционные системы, тем самым решая проблему совместимости программ и операционной системы;

- принцип комплексности предполагает, что, используя виртуальные машины при изучении компьютерных дисциплин, осуществляется полнота рассмотрения всех сторон изучения данного предмета. Чтобы действительно 
знать предмет, надо охватить, изучить все его стороны, все связи и опосредствования. Использование виртуальных машин практически исключает возможность нанесения вреда реальному компьютеру, что позволяет в виртуальной машине осуществлять любые действия;

- принции интегративности предполагает взаимосвязь всех компонентов процесса обучения, всех элементов системы, связь между системами, он является ведущим при разработке целеполагания, при определении содержания обучения, его форм и методов. Интегративность подчеркивает взаимосвязь между науками, например, использование виртуальных машин в образовательном процессе, при изучении различных дисциплин невозможно без базовых знаний информатики и вычислительной техники. Принцип интегративности способствует позволению и изучению новых наук;

- принцип связи теории с практикой - сам термин виртуальная машина связан с информационными технологиями. Изучение дисциплин, связанных с компьютерными технологиями, трудно осуществить без практического подхода. Использование виртуальных машин в образовательном процессе отталкивается от всей парадигмы образования, в частности, что теория должна подкрепляться практикой, особенно при изучении компьютерных дисциплин. То же касается и различных сфер человеческой деятельности, таких как медицина, в которой теория и практика неразрывны, или в изучении технологии, где без связи между теорией и практикой осуществление деятельности невозможно;

- принциип наглядности - в виртуальной машине можно исследовать возможности операционных систем без вреда для реального компьютера, так как виртуальная машина изолирована от операционной системы реального компьютера. Обучающийся может изучать, тестировать, в общем выполнять любые действия с операционной системой виртуальной машины, без опасений нанесения вреда операционной системе реального компьютера;

- принции систематичности, последовательности - виртуальная машина - это инструмент, средство, призванное помочь организации учебного процесса, облегчить администрирование и обслуживание реальных компьютеров. К примеру, преподавание дисциплин, связанных с администрированием компьютерных сетей, подразумевает наличие мощной материальной базы. Многие учебные задачи, важные для становления молодого специалиста, трудно реализовать в классе с 10-15 компьютерами [11, с. 75].

В связи с этим возникает потребность в использовании программных средств, призванных помочь организации учебного процесса. Одним из способов решения данной проблемы является возможность использования виртуальных машин.

Использование виртуальных машин позволяет снизить трудозатраты на администрирование учебных компьютеров. Существует огромный перечень 
необходимого учебного программного обеспечения. Виртуальные машины являются файлами, их копирование позволяет избежать непосредственной установки учебного программного обеспечения на каждый компьютер [12, с. 54].

Принцип систематичности и последовательности реализуется посредством педагогического мастерства преподавателя компьютерных дисциплин. Реализация принципов обучения с использованием виртуальных машин в образовательном процессе связана в большей степени с мастерством преподавателя, с его педагогической компетентностью, профессиональной мобильностью. Реализация дальнейших принципов целиком зависит от преподавателя.

Знание принципов обучения дает возможность организовать учебный процесс в соответствии с его закономерностями, обоснованно определить цели и отобрать содержание учебного материала, выбрать адекватные целям формы и методы обучения [13].

Требование профессионального обучения состоит в том, чтобы обеспечить получение высокой квалификации рабочего, необходимо соответствие технологического уровня процесса обучения реальному трудовому процессу.

Требования профессионально-педагогического образования направлены на подготовку компетентных выпускников, способных активно трудиться в различных сферах деятельности. В интересах профессиональной мобильности следует использовать любые средства в учебном процессе, позволяющие повысить качество, а также профессиональную мобильность обучаемого.

Виртуальные машины позволяют решать практико-ориентированный класс задач, решение которых обеспечивает у обучаемых формирование профессиональной мобильности и определяет их уровень компетентности выпускника, что делает его конкурентоспособным в современном обществе и на рынке труда в целом.

Направленность новых информационных технологий на расширение спектра решаемых учебных задач, а также их ориентированность на практическое применение позволяют улучшить качество подготовки специалистов в области компьютерных технологий. Информатизация образовательных процессов на сегодняшний день позволяет эффективно подготовить человека к жизни в современном компьютеризированном обществе.

В данной статье обозначены лишь некоторые дидактические принципы, направленные на достижение желаемого результата посредством использования виртуальных машин.

\section{Список литературы}

1. Подласый И.П. Педагогика: Новый курс: учеб. для студ. высш. учеб. заведений: в 2 кн. - М.: ВЛАДОС, 2001. - Кн. 1: Общие основы. Процесс обучения. -576 с.

2. Педагогика: учеб. пособие для студентов пед. учеб. заведений / В.А. Сластенин, И.Ф. Исаев, А.И. Мищенко, Е.Н. Шиянов. - М.: Школа-Пресс, 1998. - 512 с. 
3. Пидкасистый П.И. Педагогика: учеб. пособие для студентов пед. вузов и пед. колледжей / под ред. П.И. Пидкасистого. - М.: Изд-во Пед. общества России, 2001. $-640 \mathrm{c}$.

4. Ольхов И.А. О сформированности профессиональной мобильности у будущих бакалавров технологического образования // Материалы всерос. науч.-практ. конф. / Оренбургский гос. ун-т. - Оренбург: Изд-во ОГУ, 2010. - 277-280 с.

5. Процесс информатизации общества [Электронный ресурс] // Дистанционное обучение / Бийский технолог. ин-т. - URL: http://do.bti.secna.ru/lib/book_it/ process.html (дата обращения: 21.02.2016).

6. Виртуальные машины [Электронный ресурс]. - URL: http://all-ht.ru/inf/vpc/ p_0_0.html (дата обращения: 24.09.2015).

7. Кутыркина Г.А. Адаптация 8- и 16-битного программного обеспечения для современных 64-битных систем // Проблемы применения современных информационных технологий: материалы 4-й регион. науч.-практ. конф. студ. и аспир.; Екатеринбург 27 апр. 2011 г. / Рос. гос. проф.-пед. ун-т. - Екатеринбург, 2011. - С. 46-52.

8. Уваров А.С. Введение в виртуализацию. Ч. 1 [Электронный ресурс] // Записки IT-специалиста. - URL: http://interface31.ru/tech_it/2012/07/vvedenie-v-virtualizaciyu-chast-1.html (дата обращения: 20.02.2016).

9. Как работают виртуальные машины - принцип работы [Электронный ресурс] // Оптимизация Windows. - URL: http://winsetting.ru/kak-rabotayut-virtualnyemashiny-princip-raboty.html (дата обращения: 19.02.2016).

10. Чурилов И.А. Применение виртуальных машин в процессе обучения ИТ-специальностям // Преподавание информационных технологий в Российской Федерации: материалы Одиннадцатой открытой Всерос. конф.; 16-17 мая 2013 г. - Воронеж: Изд-во Воронеж. гос. ун-та, 2013. - С. 75-77.

11. Маринин И.С., Максимов В.А. Использование виртуальных машин в учебном процессе // Проблемы применения современных информационных технологий: материалы 4-й регион. науч.-практ. конф. студ. и аспир.; Екатеринбург 27 апр. 2011 г. / Рос. гос. проф.-пед. ун-т. - Екатеринбург, 2011. - С. 52-56.

12. Сластенин В.А., Исаев И.Ф., Шиянов Е.Н. Педагогика: учеб. пособие для студ. высш. пед. учеб. заведений / под ред. В.А. Сластенина. - М.: Академия, 2002. $576 \mathrm{c}$.

\section{References}

1. Podlasyi I.P. Pedagogika: Novyi kurs [Pedagogics: new course]. Moscow: VLADOS, 2001. Part 1. $576 \mathrm{p}$.

2. Pedagogika [Pedagogics]. V.A. Slastenin, I.F. Isaev, A.I. Mishchenko, E.N. Shiianov. Moscow: Shkola-Press, 1998. 512 p.

3. Pidkasistyi P.I. Pedagogika [Pedagogics]. Moscow: Izd-vo Ped. obshchestva Rossii, $2001.640 \mathrm{p}$.

4. Ol'khov I.A. O sformirovannosti professional'noi mobil'nosti $u$ budushchikh bakalavrov tekhnologicheskogo obrazovaniia [On professional mobility in future bachelors of technological profile]. Materialy vseros. nauch.-prakt. konf. Orenburg: Izd-vo OGU, 2010, pp. $277-280$. 
5. Protsess informatizatsii obshchestva [Process of society informatization]. Distantsionnoe obuchenie. Biiskii tekhnolog. in-t, available at: http://do.bti.secna.ru/lib/book_it/ process.html (accessed: 21.02.2016).

6. Virtual'nye mashiny [Virtual machines], available at: http://all-ht.ru/inf/vpc/ p_0_0.html (accessed: 24.09.2015).

7. Kutyrkina G.A. Adaptatsiia 8- i 16-bitnogo programmnogo obespecheniia dlia sovremennykh 64-bitnykh system [Adaptation of 8 and 16-bits software for the modern 64-bits systems]. Problemy primeneniia sovremennykh informatsi-onnykh tekhnologii: materialy 4-i region. nauch.-prakt. konf. stud. i aspir.; Ekaterinburg 27 apr. 2011. Ros. gos. prof.-ped. un-t. Yekaterinburg, 2011, pp. 46-52.

8. Uvarov A.S. Vvedenie v virtualizatsiiu. Ch. 1 [Introduction in virtualization. Part 1]. Zapiski IT-spetsialista, available at: http://interface31.ru/tech_it/2012/07/vvedenie-v-virtualizaciyu-chast-1.html (accessed: 20.02.2016).

9. Kak rabotaiut virtual'nye mashiny - printsip raboty [How virtual machines work basic principles]. Optimizatsiia Windows, available at: http://winsetting.ru/kak-rabotayutvirtualnye-mashiny-princip-raboty.html (accessed: 19.02.2016).

10. Churilov I.A. Primenenie virtual'nykh mashin v protsesse obucheniia ITspetsial'nostiam [Application of virtual machines in training IT-specialists]. Prepodavanie informatsionnykh tekhnologii v Rossiiskoi Federatsii: materialy Odinnadtsatoi otkrytoi Vseros. konf.; 16-17 May 2013. Voronezh: Izd-vo Voronezh. gos. un-ta, 2013, pp. 75-77.

11. Marinin I.S., Maksimov V.A. Ispol'zovanie virtual'nykh mashin v uchebnom protsesse [Application of virtual machines in education]. Problemy primeneniia sovremennykh informatsionnykh tekhnolo-gii: materialy 4-i region. nauch.-prakt. konf. stud. $i$ aspir.; Ekaterinburg 27 apr. 2011. Ros. gos. prof.-ped. un-t. Yekaterinburg, 2011, pp. 52-56.

12. Slastenin V.A., Isaev I.F., Shiianov E.N. Pedagogika [Pedagogics]. Ed. by V.A. Slastenin. Moscow: Akademiia, 2002. 576 p.

Получено 19.02.2016

\section{Сведения об авторе}

\section{ГИЛЕВ Владимир Михайлович}

e-mail:vovannn242@rambler.ru

системный администратор отдела развития информационных сетей и технического сопровождения, магистрант кафедры информационных систем и технологий Института инженерно-педагогического образования Российского государственного профессионально-педагогического университета (Екатеринбург, Россия)

\section{About the author}

\section{Vladimir M. GILEV}

e-mail:vovannn242@rambler.ru

System Administrator, Department of Development of Information Networks and Technical Support; Graduate Student, Department of Information Systems and Technology, Institute of Engineering and Pedagogical Education, Russian State Vocational Pedagogical University (Yekaterinburg, Russia) 